(c) American Dairy Science Association, 2003.

\title{
A Partnership of Universities and Agri-Business for an Effective Dairy Herd Management Learning Experience for Undergraduates: The Dairy Challenge
}

\author{
M. S. Weber Nielsen, J. J. Domecq, L. E. Davis, D. K. Beede, M. Budine, ${ }^{\star}$ and F. Martsolf* \\ Department of Animal Science, \\ Michigan State University, \\ East Lansing, 48824 \\ and ${ }^{*}$ Cargill Animal Nutrition, Mentone, IN 46539
}

\section{ABSTRACT}

The Dairy Challenge contest allows undergraduate students to apply knowledge gained in the classroom in an evaluation of the management practices of commercial dairy farms. University faculty partnered with industry representatives to develop the competition. Participants in the Dairy Challenge do the following: 1) critically evaluate dairy herd management practices and make recommendations for improvements; 2) visit local dairy farms and gain knowledge of different farms' management practices; 3) meet and interact with potential employers from the dairy industry during the contest; 4) evaluate herd records and utilize knowledge of dairy herd management software and computer presentation tools; 5) test their speaking, presentation, and problem-solving skills; and 6) work as a team to build consensus and tag-team speaking formats. Teams of four undergraduate students critically evaluate a commercial dairy farm using herd records, a description of farm operations, and tour of the farm facilities. The farmer answers questions pertaining to management of the farm in a group interview with all teams and in a separate interview with each individual team. Teams give a 20-min presentation that is scored on the description and assessment of the management practices and recommendations for improvements in management and facilities. Additionally, scoring is based on apparent level of preparation, speaking, presentation skills, and responses to judges' questions. The judges are university specialists and dairy industry professionals. This capstone experience allows students to interact with dairy farmers and representatives from the dairy industry and expands their knowledge and skills gained during their academic career.

Received August 14, 2002.

Accepted November 4, 2002

Corresponding author: M. S. Weber Nielsen; e-mail: msw@ msu.edu.
(Key words: undergraduate, dairy herd management, industry, university)

\section{Abbreviation key: MSU = Michigan State University . \\ INTRODUCTION}

The dairy industry has experienced a dramatic change in structure and farm management practices during the last decade. The number of dairy farms continues to decline, and the size of farms increases each year, resulting in an increasingly competitive environment for the remaining farms. At the same time, fewer young people are coming to college with a practical background in the dairy industry, increasing the need for universities to train undergraduate students in practical aspects of dairy management. Dairy industry support organizations have a strong interest in employing college graduates who have an excellent understanding of principles and practices of dairy herd management, in part because dairy farmers and industry representatives who serve them are challenged with detecting management "areas of opportunity" for increasing efficiency and profitability. Thus, to ensure a strong future for the production side of the dairy industry, it is important that undergraduate students with emphasis in dairy cattle obtain a practical and relevant education during their college career.

The best possible preparation of undergraduate students for their future careers involves experiences similar to those they will encounter in their jobs. In addition to instruction in basic principles, an undergraduate education should involve the following: critical thinking, decision-making, problem-solving, skills development, communications, cooperation, information retrieval, wisdom, and common sense (Kauffman, 1992). Moreover, individuals in one discipline will not solve the biggest challenges facing tomorrow's dairy industry. Professionals in the dairy industry must work as a team. Thus, it is important that college graduates learn to work on interdisciplinary teams while in school (Braund, 1995). 
The concept of farm evaluation has long been part of advanced dairy management classes around the nation, and this experience is often considered the capstone in the education of students with emphasis in dairy management.

At many universities, industry representatives who work daily with dairy farmers are key resources in teaching of herd evaluation and other concepts, as in the course described by Combs et al. (2001). The industry organizations and universities that serve the dairy farmers increasingly need to work together to provide a current and relevant education for future dairy leaders. The first objective of this project was to develop, in partnership with dairy industry support organizations, a competition for undergraduates based on evaluation of dairy herd management and known as the Dairy Challenge. A second objective was to examine the perceived value of the competition for students, universities, and industry sponsors.

\section{MATERIALS AND METHODS}

\section{Michigan State University (MSU) Dairy Challenge}

Contest development and sponsorship. The contest rules were developed in 2000 by Michigan State University (MSU) professors teaching senior-level dairy herd management courses and Cargill Animal Nutrition representatives with experience in farm evaluation. A key concept was that students were expected to transform data into information for evaluation and to be able to communicate the rationale for any suggested changes. A local contest was held at MSU annually beginning in 2000. Cargill Animal Nutrition provided full financial sponsorship.

Participants. The target group for the contest was undergraduate students in the final year of the program. The contest was marketed to students in animal science, agribusiness management, agricultural communications, agriscience education, and 2-yr agricultural technology programs. Students formed their own teams of four students.

Farm selection and data. Contest organizers selected contest farms on the basis of five criteria: presence of clear strengths and opportunities for improvement of the farm operation, availability of herd records in electronic format, excellent communication skills of farm managers, willingness of farms to participate, and reasonable proximity to campus. Before the contest, organizers worked with farm managers to inform them of the contest schedule, obtain copies of rations for each management group in the herd, obtain a written summary of herd production records, and to download recent production, reproduction and health from the farm's records management software program. Before the farm visit, each team was provided a notebook containing summary information on herd performance and rations for all management groups of animals. During the teams' visit to the contest farm, farm managers were asked to provide a general overview of the farm's history, management structure, and layout, and a description of management practices. Following the farm visit on the first day, teams were given electronic access through the university server to the herd's records.

Farm visit. A farm visit of approximately $1.5 \mathrm{~h}$ on the first day provided the foundation of the 2 -d contest. Teams were allowed to take a self-guided walk through the farm. For biosecurity reasons, students were asked to wear clean clothes and use disposable plastic boots. Further, to minimize potential transfer of pathogens to the farm's young stock, teams began their farm tour in the calf housing area, then proceeded to housing for heifers and cows. Students were allowed to ask questions of the manager at any time during the visit and in a 30-min group interview at the conclusion of the visit. After the farm visit, students returned to campus and had the opportunity to continue working on their analysis of the farm during the evening.

Judges. Four judges were recruited from dairy industry companies to evaluate performance of teams. Criteria for selection of judges included expertise in nutrition, health, reproduction, herd management, and farm financial management; proximity to campus and familiarity with the Michigan dairy industry; and, ability to communicate with students.

Presentations. Microsoft software was used by teams in preparing their farm analysis for presentation to a panel of judges. A microcomputer laboratory was made available to students the morning after the farm visit for records analysis and preparation of their presentation. Presentations began in the afternoon, with teams presenting in a random order. Teams developed a 20-min PowerPoint presentation with three main elements: a brief description of the farm, an analysis of strengths and challenges, and recommendations for improving farm management practices including rationale for changes. Each team member was required to present a portion of the presentation. After the presentation, there was a 10-min period for questions from the judges. Presentations were evaluated according to the scoring criteria shown in Table 1. Farm owners and employees were invited to attend the teams' presentations.

Awards. The winning team received $\$ 1,000$. The second-place team received $\$ 500$. Each participant received a polo shirt with the MSU Dairy Challenge logo. Awards were presented at the MSU Dairy Club recognition banquet that took place several weeks after the contest. Contest farms were presented with a gift of 
Table 1. Scorecard for evaluation of presentations in the MSU Dairy Challenge and the North American Intercollegiate Dairy Challenge.

\begin{tabular}{lc}
\hline Category & Points possible \\
\hline Material Presented & 10 \\
Description & \\
Clear overview of farm environment & 20 \\
Complete and accurate & 20 \\
Assessment & \\
Appropriate order of importance & \\
Correct, detailed, and justified & 20 \\
Recommendations & \\
Appropriate order of importance and justified & \\
Realistic suggestions (economical, practical) & 5 \\
Presentation and Visual Aids & 10 \\
Presence & \\
Enthusiastic, confident & \\
Maintained eye contact, few distracting mannerisms & \\
Spoke clearly with appropriate volume, speed, and grammar & \\
Visual Aids & \\
Clear, legible, organized & \\
Preparation and Organization & 15 \\
Planning and preparation by all team members & \\
Knowledge of farm practices by all team members \\
Concise statement of objectives and conclusion in logical order \\
Presented within time limit (5 points deducted/ 5 min \pm 20 min) \\
Response to Questions
\end{tabular}

appreciation of a framed and engraved print of a dairy farm scene.

Surveys. Surveys were completed by and collected from students and judges at the end of the 2001 and 2002 contests. Survey forms and responses for the 2001 MSU Dairy Challenge were presented previously (Davis et al., 2001). For each survey question, students were asked to respond using a scale from 1 (strongly disagree) to 10 (strongly agree).

\section{The North American Intercollegiate Dairy Challenge}

Contest development and leadership. Following success with the MSU Dairy Challenge, the North American Intercollegiate Dairy Challenge was developed as a national contest for undergraduate students from universities with 4-yr dairy programs. Michigan State University was selected as the host university for the first contest. Contest characteristics were similar to those of the MSU Dairy Challenge, with modifications described below. The contest began on a Friday morning and concluded with an awards banquet on Saturday evening.

A steering committee of dairy industry enthusiasts provided leadership for staging the contest. The steering committee was composed of individuals working in various areas of the dairy industry: a district sales manager in dairy nutrition, a chairman of a dairy breeding and genetics company, a vice-president of communi- cations for a dairy breeding and genetics company, a dairy farmer, a professor in dairy herd management, a dairy marketing consultant, a dairy nutrition consultant, a veterinarian with expertise in dairy management, a sales manager for a dairy breeding and genetics company, an executive director at a dairy breed foundation, a dairy industry representative near the host university (contest superintendent) and a representative of the host university (contest coordinator).

Participants. North American universities with a 4-yr dairy program were invited to participate. Each university was permitted to enter one team of four students, as well as additional students who were randomly assigned to aggregate teams representing several universities. The aggregate team concept was employed to enhance university interest in the contest and to increase the number of students participating. Representatives of dairy industry companies, MSU, and the MSU Extension Dairy Team provided assistance in preparing for and conducting the contest.

Farm selection and data. Due to the large number of participants, two farms were selected to allow for participation by more than 10 teams, with each team evaluating one of the two farms. Criteria used to select contest farms were similar to those used in the MSU Dairy Challenge. Farm 1 milked 219 cows, with a rolling herd average of 13,091 kg. Farm 2 milked 437 cows, with a rolling herd average of $13,051 \mathrm{~kg}$. Farms were located within $1 \mathrm{~h}$ of the MSU campus. Both farms 
maintained herd records electronically with records management software.

A representative copy of farm data was mailed to participating universities 1 mo before the contest. At the beginning of the contest, each team received the following written information about the farm: diagram of farmstead layout; summary of history, goals and management practices; herd summary data; rations for each management group; summary of Michigan averages for commodity feed prices, milk price, labor price, and loan rates; and, representative but fictitious farm financial information including average income and expenses and information on debt levels. Upon the teams' return from the farms to the MSU campus, each team was provided with a laptop containing the herd records in dairy records management software as well as a disk copy of the Dairy InfoBase version 4.0 (Agricultural Database for Decision Support Center, Verona, WI).

Farm visit. The contest began with a breakfast and brief orientation to the contest schedule. One half hour before departing for the farm visit, each team received a copy of the written information on the farm. Following the walk-through, teams, as one group, had the opportunity to ask the manager questions for $15 \mathrm{~min}$. After return to the MSU campus, teams worked independently for about $6 \mathrm{~h}$ to analyze herd records and to synthesize their observations into a presentation. Each team was given the opportunity to privately interview the farm manager for $12 \mathrm{~min}$. All materials and a final disk copy of the team's presentation were collected after approximately $6 \mathrm{~h}$ on Friday evening.

Judges. Judges were recruited from the dairy industry and from universities. Judges visited the contest farms and received the same data that was provided to teams. Four judges evaluated presentations from seven teams on one farm, and five judges evaluated presentations from seven teams on a second farm. Effort was made to balance the two panels of judges for their areas or expertise and for number of judges, although a change resulted in the panels having unequal numbers.

Presentations. The second day, each team received paper copies of their presentation slides 30 min before their presentation time to aid in preparation. All judges viewed the first presentation for each farm together to standardize scoring between the two sets of judges. Subsequently, presentations for the two farms took place concurrently. Presentations were staggered throughout the day approximately every $35 \mathrm{~min}$.

Sponsors. Thirty-four industry organizations contributed sponsorship for the event (Table 2). Individuals on the steering committee recruited sponsors through personal contact. Sponsorship levels were platinum, $\$ 5,000$ minimum; gold, $\$ 2,000$ minimum; and silver, $\$ 500$ minimum. Gifts in kind also supported the activi- ties and needs of the contest. Funds were used for scholarship awards, travel assistance to universities, and expenses of the contest. The National Dairy Shrine managed the collection and distribution of funds for the national contest.

Awards. All teams were ranked according to the following categories: champion, reserve champion, gold, and silver. Teams earning champion awards received $\$ 2,000$ cash scholarships. Teams earning reserve champion awards received $\$ 500$. All participants received a certificate of recognition.

Surveys. To evaluate the effectiveness of the event, data were collected at the contest from judges, coaches, students, and sponsors.

\section{RESULTS AND DISCUSSION}

\section{MSU Dairy Challenge}

Students with different backgrounds participate in extracurricular activities for a variety of reasons. Thus, it can be difficult to assess the learning value of a particular exercise and its benefit to a number of unique students. During the 3 yrs that MSU has hosted a local contest for its undergraduate students, a range from three to six teams have participated each year. To evaluate student feedback on their experience in the MSU Dairy Challenge in 2002, surveys were completed by and collected from students following their presentation to judges (Table 3; 100\% return rate). Students agreed that the contest met their overall expectations and challenged their knowledge. In addition, students believed that an appropriate amount of time was allocated for each element of the contest. Similar to previous MSU contests, students generally felt that the contest farm had apparent strengths and weaknesses that made it suitable for the Dairy Challenge. Students generally agreed that appropriate judges were chosen, but preferred that new judges be selected each year and that each company have only one representative on the judges' panel to increase diversity. On average, students agreed that the judges asked appropriate questions during the question-and-answer period and were willing to discuss issues with students. General feedback from the judges was that the contest was a challenging event for undergraduate students with the appropriate degree of rigor. Students indicated that they would encourage other students to participate in future MSU Dairy Challenge contests.

The Dairy Challenge was designed primarily as a 2d activity to test students' knowledge, with the expectation that learning and critical feedback to students occurred in their dairy-related courses. As a result, the contest provided an excellent means for evaluating strengths and needs areas of an undergraduate pro- 
Table 2. Sponsors of the 2002 North American Intercollegiate Dairy Challenge.

\begin{tabular}{ll}
\hline ABS/Genus & Monsanto Dairy Business \\
ADM Alliance Nutrition & Moore, Stephens, Fraze, and Torbet, LLP \\
Ag-Bag International & National All-Jersey, Inc./American Jersey Cattle \\
Agricultural Database for Decision Support & Association \\
(ADDS) Center & Nutrition Professionals, Inc. \\
Agri-Tech & Pfizer Animal Health \\
Alta Genetics & Pharmacia Animal Health \\
American Guernsey Association & Prince AgriProducts, Inc. \\
American Guernsey Foundation & Professional Dairy Producers of Wisconsin \\
BioProducts & Purina Mills, LLC \\
Cargill Animal Nutrition & QualiTech, Inc. \\
Cooperative Resources International (CRI) & Select Sires, Inc. \\
Cyagra & SoyPlus \\
DairyBusiness Communications & Swiss Valley Farms \\
Dairy Records Management Systems & Valley Ag Software \\
DeLaval & Vance Publishing \\
Kane Enterprises & Vita Plus Corp. \\
Merial Limited & Zinpro Corp. \\
Michigan Milk Producers Association & \\
\hline
\end{tabular}

gram in dairy management. At the same time, this type of contest achieved the important educational goal of exposing students to current industry practices, which is sometimes difficult to simulate in the classroom (Kauffman et al., 1971). Students generally considered their knowledge from course work to be adequate preparation for the contest, but were less confident in their knowledge of records management software.

In actual situations, professional consultants in the dairy industry often focus on their specific areas of expertise and evaluate herd management as part of a management team. Thus, it is important that students develop and enhance their skills needed to succeed in this setting. It has been long recognized that intercollegiate competitions stimulate student learning (Kauffman et al., 1971; Field et al., 1998). However, often not enough opportunities are given to develop these skills. Students participating in the 2002 MSU Dairy Challenge agreed the contest improved their ability to interact and work in a team setting. In addition, the contest experience improved their skills in problem solving and public speaking. These results demonstrate the impor- tance of incorporating practical, real-world experiences into the curriculum, because commercial agricultural entities place high priority on hiring individuals who can communicate well and work as part of a team, in addition to having a solid technical and practical background in dairy production and management.

\section{North American Intercollegiate Dairy Challenge}

Thirteen US universities were represented in the first North American Intercollegiate Dairy Challenge: California Polytechnic State University at San Luis Obispo, Iowa State University, Michigan State University, Pennsylvania State University, The Ohio State University, State University of New York at Morrisville, Texas A \& M University, University of Idaho, University of Minnesota, University of Wisconsin at Madison, University of Wisconsin at River Falls, Virginia Polytechnic Institute and State University, and Washington State University. Universities with 4-yr dairy programs were invited to participate, with a limit of 20 teams set the first year to ensure adequate capacity of the contest to

Table 3. Responses of students $(n=12)$ to a survey questionnaire on the 2002 MSU Dairy Challenge.

\begin{tabular}{lll}
\hline Question & Mean $^{1}$ & Range \\
\hline Event was challenging for students & 9.1 & $7-10$ \\
Contest met expectations & 8.4 & $7-10$ \\
Time for presentations was sufficient & 7.1 & $1-10$ \\
Would encourage other students to participate & 9.0 & $7-10$ \\
Student knowledge from courses was sufficient & 7.8 & $6-10$ \\
Student knowledge of computer tools was sufficient & 6.8 & $1-10$ \\
Improved problem-solving skills & 8.5 & $7-10$ \\
Improved public-speaking skills & 8.7 & $7-10$ \\
Improved ability to work in team setting & 9.1 & $7-10$ \\
Strengths and opportunities evident on farm & 8.4 & $7-10$ \\
\hline
\end{tabular}

\footnotetext{
${ }^{1}$ Scale: 1 (strongly disagree) to 10 (strongly agree). $\mathrm{N}=12$ respondents for each question.
} 
Table 4. Responses of students $(n=56)$, coaches $(n=13)$, and judges $(n=9)$ to a survey questionnaire on the 2002 North American Intercollegiate Dairy Challenge.

\begin{tabular}{|c|c|c|c|c|c|c|}
\hline \multirow[b]{2}{*}{ Question } & \multicolumn{2}{|c|}{ Students ${ }^{1}$} & \multicolumn{2}{|c|}{ Coaches $^{2}$} & \multicolumn{2}{|c|}{ Judges $^{3}$} \\
\hline & Mean $^{4}$ & SD & Mean $^{4}$ & SD & Mean $^{4}$ & SD \\
\hline Event was challenging for students & 9.2 & 0.8 & 9.1 & 1.2 & 8.8 & 1.9 \\
\hline Contest met expectations & 8.5 & 1.1 & - & - & 9.7 & 0.5 \\
\hline Time for presentations was sufficient (20 min) & 8.7 & 1.8 & 9.4 & 0.8 & 9.8 & 0.4 \\
\hline Would encourage others to participate & 9.7 & 0.6 & 9.8 & 0.4 & 9.8 & 0.4 \\
\hline Student knowledge from courses was sufficient & 8.7 & 1.3 & 7.5 & 1.7 & 7.5 & 1.9 \\
\hline Student knowledge of computer tools was sufficient & 7.8 & 1.7 & 8.2 & 1.3 & 8.3 & 1.2 \\
\hline Students' ability to work in the team setting & 9.3 & 1.0 & 9.6 & 0.5 & 9.3 & 0.8 \\
\hline Strengths and opportunities evident on farm & 8.2 & 1.4 & 8.5 & 1.0 & 7.6 & 1.5 \\
\hline Willingness of farmer to discuss issues with students & 8.3 & 1.6 & 9.3 & 1.6 & 9.5 & 0.5 \\
\hline Appropriate judges were chosen & - & - & 8.8 & 1.3 & 8.3 & 1.5 \\
\hline
\end{tabular}

provide a good experience for participants. One aggregate team consisting of four students from California Polytechnic State University, Pennsylvania State University, and Washington State University also participated in the contest, for a total of 14 teams. Before the contest, discussion took place among individuals on the steering committee, university professors, and industry representatives on whether the contest should consist of university teams, aggregate teams, or both. It was decided to allow universities to enter both a school team and additional individuals on aggregate teams in the first few national contests, and review the contest structure again in the future. Although based on surveys from only one aggregate team consisting of four students, feedback after the contest on the aggregate team concept was positive. Indeed, professionals in the dairy industry are often required to work together as a team with individuals from other backgrounds and specialties, so the aggregate team experience strengthens useful teamwork and communication skills in students.

Students, coaches, and judges responded positively to the contest experience (Table 4). Similar questions were asked of each of these groups. Survey return rate was $98 \%$ for students, $67 \%$ for judges, and $54 \%$ for coaches. The nature of the contest addresses some criticisms of judging activities (Field et al., 1998), including whether judging contests provide a realistic view of the industry, and integrate economic data with production management. The contest met overall expectations. It was viewed by students, coaches, and judges as being challenging enough for college students, and participants strongly agreed that they would encourage others to participate in the 2003 North American Intercollegiate Dairy Challenge. All groups generally agreed that students' knowledge gained from their coursework prepared them adequately for critically evaluating a farm, although some opportunity existed to enhance college courses to better prepare students. Students' level of understanding of computer tools including records management software and Microsoft programs was generally adequate. Students, coaches, and judges generally agreed that students were well-prepared to interact in a team setting. It was considered that appropriate judges were selected, with four or five judges having backgrounds in veterinary medicine, herd health, dairy herd management, breeding and genetics, and nutrition. Generally, tools of laptop computers and microcomputer laboratories provided during the contest were considered sufficient, although some need was identified in written responses for additional tools such as digital cameras. In addition, written comments from students and coaches indicated a preference for using real financial data of farms in the contest, in contrast to the fictitious financial data used in the national contest. In a question requiring a written response, students, coaches, and judges were unanimously positive in their response to the question of whether the contest should be continued.

Similar to other judging activities (Field et al., 1998), institutional support was combined with donations from other sources to fund student participation in the contest. As a capstone experience, the contest should help facilitate students' transition from college to their future careers in the dairy industry (Andreasen and Trede, 2000), and thus better prepare students to be productive employees. It is noteworthy that sponsors, including many employers of students on internships and in jobs, contributed funds to cover costs of the contest and to offset travel costs for all participating universities. Sponsors also facilitated conversion of some farm data into formats appropriate for use in two different records management software programs. Sponsors 
Table 5. Responses of sponsors $(n=15)$ to survey questionnaire on the 2002 North American Intercollegiate Dairy Challenge.

\begin{tabular}{lll}
\hline Question & Mean $^{1}$ & SD \\
\hline Format allowed time for contact with students & 8.9 & 1.1 \\
Contest helped my company to identify good job & & 1.7 \\
$\quad$ candidates & 7.6 & 1.6 \\
Contest was a valuable use of time & 8.2 & 1.4 \\
My company plans to continue its sponsorship & 8.8 & 1.8 \\
Three sponsorship levels were appropriate & 8.1 & 1.2 \\
Having a national contest is extremely important & 9.0 & 2.0 \\
Having several regional contests instead of a single & & 2.8 \\
national contest is extremely important & & 2.2 \\
Having regional contests and a national contest is & 7.3 & \\
extremely important &
\end{tabular}

${ }^{1}$ Scale: 1 (strongly disagree) to 10 (strongly agree). $\mathrm{N}=9$ respondents for each question.

were surveyed to evaluate their opinions of the contest (Table 5). The number of sponsor representatives in attendance was approximately 15 , with 10 of those in attendance returning the survey. Sponsors considered that the sponsorship levels of platinum $(\$ 5,000)$, gold $(\$ 2,000)$, and silver $(\$ 500)$ were appropriate. At the contest, undergraduate students with interests in dairy industry careers were encouraged to interact with sponsor representatives. Opportunities for interaction were scheduled into the contest: an informal dinner following preparation of team presentations, an informal mixer during presentations where students could view sponsor booths and speak with sponsor representatives, and an informal social hour before the awards banquet. Sponsors believed that the format of the contest allowed sufficient time to interact with students, and that having representation at the contest was a valuable use of their time. On average, sponsors did feel that the contest helped their company identify good job candidates, through the opportunity to observe students in a real life situation, and they planned to continue their sponsorship. For future contests, sponsors agreed that it was important to have a single national contest and did not favor an alternative option of having several regional contests instead of a national contest. However, sponsors responded positively on average to the question of whether both regional contests and a national contest should be held. The national contest is expected to continue, with universities hosting the contest for two successive years.

\section{CONCLUSIONS}

The number of students who enroll in undergraduate dairy programs with a significant practical background in dairy management is decreasing. The concept of the Dairy Challenge is an effective method for testing and increasing students' knowledge level, problem-solving skills, ability to work in a team, and ability to give and justify recommendations for improvement to dairy farmers. Further, the Dairy Challenge provides students with an opportunity to demonstrate their knowledge and skills to potential employers. The industry that will hire many of these students has collaborated with universities to develop the Dairy Challenge as an educational competition that is beneficial to undergraduate student education and relevant to the dairy industry. The industry-university partnership and the concept of the Dairy Challenge may have potential for use in other aspects of agricultural education.

\section{REFERENCES}

Andreasen, R. J., and L. D. Trede. 2000. Perceived benefits of an agricultural capstone course at Iowa State University. Nat. Assoc. Colleges Teachers Agric. J. 44:51-56.

Braund, D. G. 1995. Changing paradigms in animal agriculture: the role of academia and industry in technology transfer. J. Anim. Sci. 73:3173-3177.

Combs, D. K., G. E. Shook, and M. C. Wiltbank. 2001. Development of a capstone course in dairy herd management. J. Anim. Sci. 79 (Suppl. 1):124-125.

Davis, L. E., F. M. Martsolf, J. J. Domecq, and M. S. Weber. 2001. Dairy Challenge: a competitive and educational experience in evaluation of dairy herd management. J. Dairy Sci. 84 (Suppl. 1): 165 .

Field, T. G., R. D. Green, J. A. Gosey, H. D. Ritchie, and S. Radakovich. 1998. A summary of intercollegiate judging activity, funding and philosophy. National Association Colleges Teachers of Agriculture J. 42:27-31.

Kauffman, R. G., J. F. Thompson, D. B. Anderson, and R. E. Smith. 1971. Improving the effectiveness of teaching animal science. J. Anim. Sci. 32:161-164.

Kauffman, R. G. 1992. Modernizing the animal science curriculum: Is change needed? J. Anim. Sci. 70:2593-2596. 